\title{
The role of IGF binding protein-3 as a parameter of activity in acromegalic patients
}

\author{
I Halperin, R Casamitjana ${ }^{1}$, L Flores, M Fernandez-Balsells and E Vilardell \\ Department of Endocrinology and ${ }^{1}$ Hormonal Department, Hospital Clinic, Barcelona University, Spain \\ (Correspondence should be addressed to I Halperin, Endocrinology Department, Hospital Clinic, Villarroel 170, O8036 Barcelona, Spain; \\ Email: ihalperi@medicina.ub.es)
}

\begin{abstract}
Objective: The production of insulin-like growth factor binding protein-3 (IGFBP-3), the main IGF-I binding protein, is regulated by $\mathrm{GH}$, and its serum levels are increased in acromegaly. We investigated its potential value as a parameter of acromegaly activity or remission in comparison with IGF-I, taking GH supression below $2 \mu \mathrm{g} / \mathrm{l}$ after glucose load as the normal standard.

Methods: Data from 40 acromegalic patients (12 males and 28 females, aged 28 to 79 years) were obtained retrospectively from stored samples. From these, 145 pairs of IGF-I/IGFBP-3 values were collected; in 67 of them, simultaneous measurement of $\mathrm{GH}$ after glucose loading allowed their classification as active or inactive acromegaly. Relationships between IGF-I, IGFBP-3 and GH after glucose load were assessed, as well as differences between IGF-I and IGFBP-3 levels in active and inactive acromegaly.

Results: Significant positive correlation between IGF-I and IGFBP-3 in 145 samples was observed $(r=0.49, P<0.0001)$. As for the 67 samples in which activity or remission could be defined in terms of GH after glucose load, 50 were active and 17 inactive. Both IGF-I and IGFBP-3 significantly correlated with minimum GH $(r=0.53, P<0.0001$ and $r=0.41, P<0.001$ respectively). For both parameters, significant differences of means between active and inactive cases were observed $(623 \pm 296$ vs $300 \pm 108 \mathrm{ng} / \mathrm{ml}, P<0.0001$ for IGF-I, and $4.1 \pm 1.3 \mathrm{vs} 3.2 \pm 0.9 \mu \mathrm{g} / \mathrm{ml}, P<0.006$ for IGFBP-3). Yet, when comparing in individual cases their classification as active or inactive with the finding of normal or increased IGF-I and IGFBP-3, among active cases 16\% appeared as normal according to IGF-I, and $50 \%$ appeared as normal in terms of IGFBP-3. Among inactive cases, $23.5 \%$ appeared as active according to IGF-I, while $17.5 \%$ appeared as active in terms of IGFBP-3.

Conclusion: Even though IGFBP-3 reflects GH secretion, it offers no advantage over IGF-I in the assessment of acromegaly, and it may underestimate disease activity in acromegalic patients.
\end{abstract}

European Journal of Endocrinology 141 145-148

\section{Introduction}

The diagnosis of acromegaly is presently based on the demonstration of high growth hormone $(\mathrm{GH})$ production; this is achieved by detection of high $\mathrm{GH}$ levels which fail to suppress after glucose load and which remain abnormally high throughout repeated samples obtained during the day, and by the finding of high insulin-like growth factor (IGF)-I levels $(1,2)$. Once the disease is diagnosed and therapy is started (either surgery, radiotherapy, drug therapy, or, most frequently, a combination of more than one therapeutic approach), disease activity must be periodically assessed. From a practical point of view, assessment of acromegaly is not free from problems: GH profiles are difficult to perform in most clinical setups, glucose load may not be convenient in diabetics (a common condition in acromegaly), and
IGF-I, while generally well correlated with 24-h GH secretion, may sometimes be discordant, as has been observed in long-term follow-up of irradiated acromegalics, in whom elevated IGF-I levels persist in spite of normalized mean plasma GH (3). Therefore, great interest has focused on the possible role of insulin-like growth factor binding protein (IGFBP)-3 as a parameter of $\mathrm{GH}$ hypersecretion.

IGFBP-3 is the major circulating IGF-I binding protein; $75 \%$ of circulating IGF-I is bound with it and with an acid-labile subunit (4), forming a ternary complex. Even though it is GH-dependent, it lacks GH pulsatility since its half life is quite long, so that its plasma levels remain stable throughout the day (5). In 1995 Grinspoon et al. (6) first observed that IGFBP-3 was increased in acromegaly and normalized when this condition was resolved. Since then, efforts have been 
aimed towards determining its role in both the diagnostic workup and in the evaluation of therapeutic results in acromegalic patients. Up to now, results have been controversial.

The aim of this study was to assess IGFBP-3 as a parameter of acromegaly activity or remission in comparison with IGF-I both at diagnosis and during follow-up of acromegalic patients, considering $\mathrm{GH}$ suppression after glucose load as the standard indicator of disease status.

\section{Materials and methods}

\section{Subjects}

Data from 40 acromegalic patients (12 males and 28 females, aged 28 to 79 years) were collected retrospectively. Samples had been obtained between 1993 and 1997, either at diagnosis (from 11 patients only), or at follow-up, during which they were submitted to surgery and/or radiotherapy, and/or pharmacological therapy. All samples were obtained between $0800 \mathrm{~h}$ and $1000 \mathrm{~h}$ after an overnight fast. Each patient contributed a different number of samples, ranging from 1 to 10 . In total, 145 pairs of IGF-I/IGFBP-3 values were obtained; in 67 of them, simultaneous measurement of $\mathrm{GH}$ after glucose load allowed characterization of acromegaly as active or inactive. These 67 glucose loads originated from 35 patients ( 1 to 3 tests from each, the first of them at baseline, before any treatment).

\section{Assays}

GH was measured by DPC Immulite System (Los Angeles, CA, USA), with intra-assay and interassay coefficients of variation of $3.8 \%$ and $6.2 \%$ respectively; levels $\leq 2 \mu \mathrm{g} / \mathrm{l}$ after $75 \mathrm{~g}$ oral glucose were considered normal. IGF-I was determined after protein extraction by RIA, with a Nichols Institute kit (San Juan Capistrano, CA, USA); intra-assay and interassay coefficients of variation were $5.2 \%$ and $8.4 \%$ respectively; levels $\leq 333 \mathrm{ng} / \mathrm{ml}$ were considered normal for subjects older than 25 years (which included all our population). IGFBP-3 was determined by RIA, with a Nichols Institute kit; intra-assay and interassay coefficents of variation were $3 \%$ and $5.9 \%$ respectively; normality was $2.0-4.0 \mu \mathrm{g} / \mathrm{ml}$ for subjects 19 to 55 years old, and $0.9-3.7 \mu \mathrm{g} / \mathrm{ml}$ for those subjects older than 56 years.

\section{Statistics}

Results are expressed as means \pm s.D.. Relationships between IGF-I, IGFBP-3, and GH after glucose load were assessed by Pearson bivariate correlation test. Differences between means were assessed by Student's two tailed $t$-test. Association of qualitative parameters was assessed by chi-square test. Statistical significance

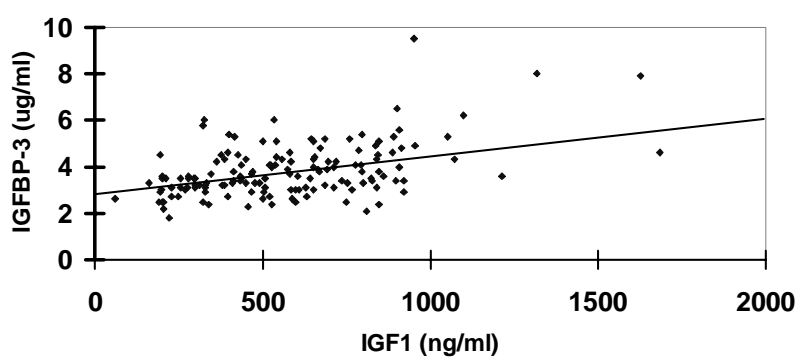

Figure 1 Correlation between IGF-I and IGFBP-3 in 145 samples from 40 acromegalic patients. $r=0.49, P<0.0001$.

was defined as $P<0.05$. All statistics were performed with software program SPSS for Windows (SPSS Inc., USA, release 6.0).

\section{Results}

The analysis of 145 pairs of IGF-I/IGFBP-3 values yielded a significant correlation between both parameters $(r=0.49, P<0.0001)$ (Fig. 1). As for the 67 samples in which activity or remission could be defined by the simultaneous measurement of GH after glucose load, 50 were characterized as active $(\mathrm{GH}>2 \mu \mathrm{g} / \mathrm{l})$, and 17 were found to be inactive $(\mathrm{GH} \leq 2 \mu \mathrm{g} / \mathrm{l})$. Both IGF-I and IGFBP-3 correlated significantly with $\mathrm{GH}$ after glucose load $(r=0.53, P<0.0001$ for IGF-I, $r=0.41$, $P<0.001$ for IGFBP-3).

Significant differences of means between active and inactive subjects were observed for both parameters. Mean IGF-I concentration was $623 \pm 296 \mathrm{ng} / \mathrm{ml}$ in active acromegalics, vs $300 \pm 108 \mathrm{ng} / \mathrm{ml}$ when the disease was inactive $(P<0.0001)$. Mean IGFBP-3 concentration was $4.1 \pm 1.3 \mu \mathrm{g} / \mathrm{ml}$ in active disease, vs $3.2 \pm 0.9 \mu \mathrm{g} / \mathrm{ml}$ for inactive subjects $(P<0.006)$. Yet when we classified individual cases as active or inactive according to their $\mathrm{GH}$ level after glucose, and compared this with the finding of either normal or increased IGF-I or IGFBP-3, important overlaps appeared, which are summarized in Table 1. According to IGF-I levels, 16\% of active acromegalics were normal, and $23.5 \%$ of inactive subjects appeared as active. As for IGFBP-3

Table 1 Prediction of activity or inactivity of acromegaly by IGF-I and IGFBP-3.

\begin{tabular}{|c|c|c|c|c|c|}
\hline & \multicolumn{2}{|c|}{ Inactive } & \multicolumn{2}{|c|}{ Active } & \multirow[b]{2}{*}{ Total number } \\
\hline & $n$ & $(\%)$ & $n$ & $(\%)$ & \\
\hline Normal IGF-I & 13 & (76.5) & 8 & (16) & 21 \\
\hline High IGF-I & 4 & (23.5) & 42 & (84) & 46 \\
\hline Total & 17 & $(100)$ & 50 & (100) & 67 \\
\hline Normal IGFBP-3 & 14 & $(73)$ & 25 & $(50)$ & 39 \\
\hline High IGFBP-3 & 3 & $(17)$ & 25 & $(50)$ & 28 \\
\hline Total & 17 & (100) & 50 & (100) & 67 \\
\hline
\end{tabular}


levels, $50 \%$ of active acromegalics had normal levels, while $17.5 \%$ of inactive subjects were regarded as elevated. Thus, IGFBP-3 underestimated disease activity in as much as half of our samples, while both parameters remained elevated in less than one quarter of inactive acromegalics. When assessed by chi-square test in cured or active acromegaly determined by $\mathrm{GH}$ level after glucose load, IGF-I showed a very significant association $\left(\chi^{2}=21.2, P<0.005\right.$ for 1 degree of freedom), while IGFBP-3 had a less significant association $\left(\chi^{2}=5.6, P<0.02\right.$ for 1 degree of freedom).

\section{Discussion}

GH secretion assessment at diagnosis of acromegaly and during its follow-up is accomplished by measurement of $\mathrm{GH}$ levels either after glucose load or in repeated sampling throughout the day, and by IGF-I levels. The cut-off for considering $\mathrm{GH}$ as normal has changed with time; at present, values $\leq 2 \mu \mathrm{g} / \mathrm{l}$ after glucose challenge are generally accepted, although there is a tendency to lower this value to $1 \mu \mathrm{g} / \mathrm{l}$, which is thought to be nearer to physiological secretion. The underlying concept is that $\mathrm{GH}$ in adults is almost undetectable except during sleep or under stimulation. Many of the discrepancies found when other parameters (IGF-I, IGFBP-3) are compared with $\mathrm{GH}$ standards are due to differences in what is considered as normal GH. When reviewing previous work on the role of IGFBP-3 in acromegaly, we found that Grinspoon et al. (6) considered $2 \mu \mathrm{g} / \mathrm{l}$ after glucose as normal; de Herder et al. (7) did not specify their GH standard but included patients with mean 24$\mathrm{h}$ GH levels $\geq 7 \mu \mathrm{g} / \mathrm{l}$; Jørgensen et al. (8) based the diagnosis of acromegaly on mean $\mathrm{GH} \geq 10 \mu \mathrm{g} / \mathrm{l}$, and considered remission to have occurred with a mean $\mathrm{GH} \leq 4 \mu \mathrm{g} / \mathrm{l}$; Páramo et al. (9) considered $\mathrm{GH} \leq 2 \mu \mathrm{g} / \mathrm{l}$ after glucose load as normal. Van der Lely et al. (10), who studied a larger group including the patients described in (7), considered GH profiles, but did not define a lower limit for disease activity. All authors agree, as we do in agreement with our results, that there is a close correlation between GH and IGFBP-3. This is not surprising, as GH regulates IGFBP-3 levels as well as IGF-I and the acid-labile subunit (ALS) which form the ternary complex found in serum (4). The point to be discussed is whether it contributes to the diagnosis of GH-secreting pituitary adenomas and, what is even more important from a practical point of view, to the assessment of therapeutic results during follow-up, which must often be life-long. In considering our results we have stuck to the $\leq 2 \mu \mathrm{g} / \mathrm{l}$ cut-off point for $\mathrm{GH}$ after glucose load, as this is the level we have actually used for clinical decisions during the study period. Had we considered a lower GH level, we would have found even more normal IGFBP-3 values in active acromegalics. Nevertheless, the standard we use for normal $\mathrm{GH}$ after glucose load is likely to be changed in the near future.
IGF-I has been extensively used in acromegaly assessment, and there are still some difficulties in the interpretation of results in some specific situations. For example, it has been postulated that elevated IGF-I may persist after radiotherapy while mean plasma $\mathrm{GH}$ returns to normal (3). Once more, this discrepancy may be attributed, at least in part, to the criteria by which normalization of somatotropic function is defined. Extreme ages may also limit its value. In childhood or adolescence normal values are not so strictly established, and bone age or pubertal stage must be considered together with chronological age. In elderly subjects IGF-I concentrations tend to be lower both in normal subjects and in acromegalics. As IGFBP3 also decreases with age, free IGF-I remains unmodified, and could be a better, age-independent parameter (10), although there is little experience in its measurement in acromegaly.

The finding and characterization of the IGF binding proteins has brought great insight into the physiology and regulation of GH actions. Also, IGFBP-3 may be useful in the clinical assessment of GH deficiency. Yet, contradictory results have been published in relation to acromegaly. Early work by Jørgensen et al. (8), although adding important information on changes in IGF-I, IGFII, and their binding proteins $-1,-2$ and -3 , is difficult to compare with other sources due to their criteria of active and cured acromegaly, as we mentioned previously. The work by Grinspoon et al. (6) considered IGFBP-3 a good parameter both at diagnosis and during follow-up. Yet, these findings have not been confirmed by later investigations. In 1995, de Herder et al. (7) stated that IGFBP-3 added no information to that offered by IGF-I. In 1997, Páramo et al. (9) found that IGF-I was better than both IGFBP-3 and the ratio of IGFI/IGFBP-3 as a parameter of clinical activity. In our work, we were not able to separate results at diagnosis from those during follow-up, since our data from the time of diagnosis came from a very small group of patients (only 11, and with no follow-up in 2 of them); IGF-I and IGFBP-3 were comparable in defining curability, but IGF-I was clearly superior to IGFBP-3 in the characterization of active disease. In fact, half of our active patients would be considered normal in terms of IGFBP-3, which is quite close to the 5/16 found by Páramo et al. It may be argued that we do not present a specific age-matched control group for IGF-I and IGFBP3 values. Yet normalities were stratified according to age, so that we expect to have no bias. Therefore, we consider that IGFBP-3 has no advantage over IGF-I, and its use for routine assessment of acromegaly activity during follow-up is not warranted. As for prognosis of acromegaly, changes in morbidity and mortality after treatment have only been evaluated in relation to $\mathrm{GH}$ levels (11-13), and no data are available based on either IGF-I or IGFBP-3 levels. The most recent of these studies, by Orme et al. (13) confirms that increased mortality rates due to cardiovascular disease and 
malignancies normalize when $\mathrm{GH}$ gets to $2.5 \mathrm{mg} / \mathrm{l}$ or lower. In their recent guidelines for the treatment of acromegaly, Melmed et al. (14) insist on this point, and define biochemical cure as $\mathrm{GH}<2 \mu \mathrm{g} / \mathrm{l}$ after glucose load, even though they state that it may not be so when IGF-I remains elevated and there is clinical evidence of disease activity.

In conclusion, we consider that IGFBP-3 adds no new information about GH status in acromegaly, and may mislead our assessment during follow-up as it underestimates persistent activity. Perhaps the measurement of free IGF-I, not influenced by the physiological effect of age on both IGF-I and IGFBP-3, may overcome some of the limitations presented by these parameters.

\section{References}

1 Melmed S. Acromegaly. New England Journal of Medicine 1990322 966-977.

2 Melmed S, Ho K, Klibanski A, Reichlin S \& Thorner M. Recent advances in pathogenesis, diagnosis and management of acromegaly. Journal of Clinical Endocrinology and Metabolism $1995803395-3402$.

3 Barkan AL, Halasz I, Dornfeld KJ, Jaffe CA, De Mott Friberg R, Chandler WF et al. Pituitary irradiation is ineffective in normalizing plasma insulin-like growth factor I in patients with acromegaly. Journal of Clinical Endocrinology and Metabolism 199782 3187-3191.

4 Khosravi MJ, Diamandi A, Mistry J, Krishna RG \& Khare A. Acidlabile subunit of human insulin-like growth factor-binding protein complex: measurement, molecular and clinical evaluation. Journal of Clinical Endocrinology and Metabolism 199782 3944-3951.

5 Jones JI \& Clemmons DR. Insulin-like growth factors and their binding proteins: biological actions (Review). Endocrine Reviews $1995163-34$
6 Grinspoon S, Clemmons D, Swearingen B \& Klibanski A. Serum insulin-like growth factor-binding protein-3 levels in the diagnosis of acromegaly. Journal of Clinical Endocrinology and Metabolism $199580927-932$.

7 de Herder WW, van der Lely AJ, Janssen JAMJL, Uitterlinden P, Hofland LJ \& Lamberts SWJ. IGFBP-3 is a poor parameter for assessment of clinical activity in acromegaly. Clinical Endocrinology $199543501-505$.

8 Jørgensen JOL, Møller N, Møller J, Weeke J \& Blum WF. Insulin-like growth factor (IGF) - I and - II and IGF binding protein -1 and -3 in patients with acromegaly before and after adenoectomy. Metabolism 199443 579-583.

9 Páramo C, Andrade MA, Fluiters E, Luna R, de la Fuente J \& García-Mayor RV. Comparative study of insulin-like growth factorI (IGF-I) and IGF-binding protein-3 (IGFBP-3) level and IGF-I/ IGFBP-3 ratio measurements and their relationship with an index of clinical activity in the management of patients with acromegaly. Metabolism 199746 494-498.

10 van der Lely AJ, de Herder WW, Janssen JAMJL \& Lamberts SWJ. Acromegaly; the significance of serum total and free IGF-I and IGF-binding protein-3 in diagnosis. Journal of Endocrinology 1997 155 9-13.

11 Bates AS, Van't Hoff W, Jones JM \& Clayton RN. An audit of outcome of treatment in acromegaly. Quarterly Journal of Medicine $199386293-299$.

12 Rajasoorya C, Holdaway MI, Wrightson P, Scorr DJ \& Ibbertson AK. Determinants of clinical outcome and survival in acromegaly. Clinical Endocrinology 199441 95-102.

13 Orme SM, McNally RJQ, Cartwright RA \& Belchetz PE. Mortality and cancer incidence in acromegaly: a retrospective cohort study. Journal of Clinical Endocrinology and Metabolism 199883 2730-2734.

14 Melmed S, Jackson I, Kleinberg D \& Klibanski A. Current treatment guidelines for acromegaly. Journal of Clinical Endocrinology and Metabolism 199883 2646-2652.

Received 2 November 1998

Accepted 19 April 1999 